WISSENSCHAFTSZENTRUM BERLIN FÜR SOZIALFORSCHUNG

SOCIAL SCIENCE RESEARCH CENTER BERLIN

Áron Kiss

Coalition Politics and Accountability

SP || $2009-01$

February 2009

ISSN Nr. $0722-6748$

Research Area

Markets and Politics

Research Unit

Market Processes and Governance
Schwerpunkt

Märkte und Politik

Abteilung

Marktprozesse und Steuerung 
Zitierweise/Citation:

Áron Kiss, Coalition Politics and Accountability,

Discussion Paper SP || 2009 - 01, Wissenschaftszentrum Berlin, 2009.

Wissenschaftszentrum Berlin für Sozialforschung gGmbH, Reichpietschufer 50, 10785 Berlin, Germany, Tel. (030) 25491 - 0 Internet: www.wzb.eu 


\title{
Coalition Politics and Accountability
}

\author{
by Áron Kiss*
}

The paper introduces the possibility of coalition government into the theoretical study of political accountability and analyzes the accountability of coalitions as a problem of team production. It is shown that coalition governments can be held accountable in the presence of an electoral alternative. Accountability becomes problematic if it is certain that at least one of the coalition parties stays in power after the elections. Such a coalition (sometimes called a 'unity government') cannot be given appropriate collective incentives. To incentivize government performance, voters make one coalition party responsible for the outcome. This, however, makes the other coalition party interested in sabotage. The paper analyzes the resulting conflict and characterizes optimal voter strategy.

\section{ZUSAMMENFASSUNG}

\section{Politische Koalitionen und Verantwortung}

In dieser Arbeit wird die theoretische Analyse der politischen Verantwortlichkeit auf die Situation einer Koalitionsregierung angewandt. Reduziert auf den vertragstheoretischen Kern des Problems stellen Koalitionsregierungen ein 'Teamprodukt' für den Wähler als Prinzipal her, wobei der 'Vertrag' zwischen Wählern und Koalitionsregierung sehr spezifisch und jedenfalls unvollständig ist. Es wird gezeigt, dass die Disziplinierbarkeit einer Koalition unproblematisch ist, wenn eine wahre Wahlalternative vorhanden ist. Die Disziplinierbarkeit (also die politische Verantwortlichkeit) wird problematisch in einer Situation, in der sich eine Koalition verschiedener Parteien ergibt, zu der es keine echte mehrheitsfähige Alternative gibt, und die als 'Große Koalition' bezeichnet werden soll. Die Besonderheit der Großen Koalition ist, dass mindestens eine der beteiligten Parteien mit Sicherheit nach den nächsten Wahlen weiterregiert. Nur Teile der Regierung können abgewählt werden; die große Koalition als Einheit kann in dieser Situation von den Wählern nicht in toto 'belohnt' oder 'bestraft' werden. Die Arbeit beschreibt die beste Strategie des repräsentativen

\footnotetext{
* I would like to thank Kai A. Konrad, Johannes Münster, Marie-Laure Breuillé, Benny Geys, Florian Morath, two anonymous referees and the Editor for useful comments and suggestions. I profited greatly from discussions with Helmut Bester, Raji Jayaraman, Dan Kovenock, Daniel Kraehmer, Dalia Marin, Oz Shy, Konrad Stahl, Roland Strausz, Jean Tirole, and participants of the SMYE 2007 in Hamburg; the BGPE Conference 'Incentives' in Nuremberg, 2007; the Workshop in Political Economy in Dresden, 2007; the IIPF Conference in Maastricht, 2008; the Meeting of the German Economic Association (VfS) in Graz, 2008; and the SFB/TR-15 Conference in Frauenwörth, 2008. This research was supported by the German Science Foundation (DFG) project SFB TR-15. All remaining errors are mine.
} 
Wählers in einem stilisierten politischen System, in dem die 'Große Koalition' regiert. Es wird gezeigt, dass der Wähler den Regierungspolitikern nur dann Anreize setzen kann, wenn er eine der Regierungsparteien für die Regierungspolitik verantwortlich macht. Dies führt jedoch zu einem Konflikt zwischen den Regierungsparteien, weil es die jeweils andere Regierungspartei zu Sabotage animiert. 


\section{Introduction}

Do coalition governments suffer from an accountability deficit? When do elections provide the right incentives to coalition governments and when do they fail to do so? Are there situations when reelection incentives induce a conflict among government parties? These questions are addressed in the present paper in a simple model of political accountability.

The accountability deficit of coalition governments is a significant, but often implicit, theoretical hypothesis behind many empirical studies in public finance and political economics. In the study of public debt, many explanations for why coalition governments may run higher budget deficits refer to inefficiencies of coalition decision making. Such explanations include the collective action problem (or 'common pool' problem) in the spending of public funds, the lack of commitment power of coalition partners, and the large number of veto players. ${ }^{1}$ These arguments, however, do not take into account the influence of elections on the actions of governments. If there is a high probability that voters remove governments after poor outcomes, coalitions have an incentive to solve the collective action problem.

The paper introduces the possibility of coalition government (a government that consists of more than one decision maker) into the theoretical study of political accountability and analyzes the accountability of coalitions as a problem of team production. Building on analyses by Barro (1973), Ferejohn (1986) and Persson and Tabellini (2000, Ch. 4), it concentrates on the moralhazard aspect of electoral politics. Voters can give incentives to government with the prospect of reelection: they reelect the incumbent if government 'output' is high enough. To assess the accountability of coalition governments the question is asked: Do voters have to settle for a lower government output if government consists of more than one decision maker?

Two main results emerge from the analysis. First, coalition government in itself does not hamper political accountability. Coalition governments can be given appropriate (collective) incentives as long as, in the presence of an electoral alternative, the coalition as a whole can be voted out of power. The reason is that reelection conditional on government performance works like a discrete team bonus, the type of contract between the principal (voters) and the team of agents (coalition government) that was shown by Holmstrom (1982) to solve the moral hazard problem in teams.

The second main finding is that the accountability of a coalition government becomes problematic when, in the absence of a real electoral alternative, the government cannot be removed as a whole. In this case coalition parties cannot be given appropriate team incentives. To incen-

\footnotetext{
${ }^{1}$ These arguments have been put forward in the seminal work by Roubini and Sachs (1989). The robustness of the 'weak government hypothesis', as they proposed it, is disputed by de Haan and Sturm (1997). Volkering and de Haan (2001) find a positive effect of government fragmentation on debt and debt growth in OECD countries. Ashworth et al. (2005) and Solé-Ollé (2006) find supporting evidence for the hypothesis for Flemish and Spanish municipalities, respectively, while the former provide a survey of the literature. Recent studies on the occurrence and success of fiscal adjustments find some, but unstable, effect of coalition governments (see Mierau et al. 2007; Illera and Mulas-Granados 2008).
} 
tivize government performance, voters have to make one of the coalition parties responsible for the outcome. This creates incentives for the other party to reduce government performance (or engage in 'sabotage'). In this way, a conflict emerges between the coalition parties, taking the form of a socially costly contest. The resulting contest between the parties is most closely related to a tournament with a 'handicap' or 'head-start advantage' analyzed by Konrad (2002). As a difference to that paper, where the handicap is an exogenous effect related to technology, here it is endogenously determined by the voters' strategy. Accordingly, this paper characterizes the 'optimal handicap' as chosen by the voters. It is shown that voters can secure a positive expected payoff even when facing this type of coalition. It is, however, as low as one-fourth of the payoff that voters can get in the presence of an electoral alternative.

The government form corresponding to this theoretical description is the 'unity government' or, as it is known in some countries, the 'Grand Coalition,' a coalition including the major centre-left and -right parties of a political system. In line with the theoretical analysis, 'unity government' can be defined as a situation where it is certain that (at least) one of the government parties stays in power after the next election. Such governments played an important role in the recent political history of Austria (1945-66, 1987-2000, 2007-), Germany (1966-69 and 2005-), Israel (1984-90 and 2001-03) and Italy (before 1991). In most of these cases the major centre-left and -right forces formed a coalition because neither bloc achieved a majority in the presence of 'extreme' or 'antisystem' parties. ${ }^{2}$

Since coalition government is a characteristic government form of proportional electoral systems, the analysis has some, decidedly modest, normative implications for the study of proportional representation (PR). According to the analysis the Achilles' heel of PR is that the emergence of 'extreme' parties disrupts the alternation of governments, forcing the formation of a unity government. A political system based on PR can thus benefit from the moderation and accommodation of 'extreme' movements: it can preserve the possibility of alternating governments and, with that, government accountability. While the analysis identifies the benefit, the potential costs of trusting 'extreme' movements with government responsibilities are also apparent, even if they may vary from case to case. A successful process of moderation and accommodation happened in the case of Communist parties in many European countries and, less controversially, in the case of Green parties. Such an outcome cannot be seen in the case of the extreme right movements of Europe.

The analysis is not meant to decide the question of choice between electoral rules. Nonetheless, it does provide a more satisfying theoretical argument about the possible weakness of coalition governments (and perhaps of PR) than conventional references to the inefficiencies of coalition governments, since it takes into account the role of elections.

Beside the weak government hypothesis discussed above, the present paper is related to three

\footnotetext{
${ }^{2}$ See Geys et al. (2006) for a study of an extreme party's effect on coalition formation in Belgian local elections. For an overview of the theories and stylized facts of coalition government in the European context see the monograph of Laver and Schofield (1990).
} 
branches of literature in economics and political science. First, it intends to contribute to the literature on political accountability by introducing coalition government into the field of study. The theoretical analysis of political accountability was initiated by the work of Barro (1973) and Ferejohn (1986) as a study of moral hazard in electoral politics. ${ }^{3}$ While in most studies the ability of voters to hold politicians accountable is welfare-improving, in recent papers, Maskin and Tirole (2004) and Dewatripont and Seabright (2006) point out potential weaknesses of political accountability. Most related to the present paper is the analysis by Persson, Roland and Tabellini (1997) who, similarly to the present paper, also study the accountability of multiple decision makers (politicians). In their framework, however, both decision makers are accountable separately to the electorate, similarly to the president and the legislature in a presidential system. This arrangement allows the authors to analyze the effect of 'checks and balances' in a political system. In our framework, the decision-makers are part of the same elected body, and therefore cannot provide checks and balances against one another. For an overview of the issues related to political accountability see Persson and Tabellini (2000) and Besley (2006).

Second, the analysis is related to several fields in the theory of incentives. The theory of moral hazard in teams is relevant for the accountability of coalitions with electoral alternative. Recent studies, following the seminal work of Holmstrom (1982), include Itoh (1991), Che und Yoo (2001), and Battaglini (2006). The theory of all-pay auctions becomes relevant in the case where a conflict emerges between the parties of the unity government. This type of contest was thoroughly analyzed by Hillman and Riley (1989), Hirshleifer and Riley (1992), and Baye, Kovenock and de Vries (1996). As described above, the present paper extends work by Konrad (2002) on allpay auctions with a 'handicap' or 'headstart advantage'. Lazear (1989) provided an early and influential analysis of sabotage in contests. More recent analyses include Konrad (2000), Chen (2003), and Münster (2007). Our setup differs from these in that sabotage is not described as a separate (second) instrument of the players, but rather as adverse effort. The terminology is used because this counter-effort hurts government performance.

Last, the paper is related to the literature on retrospective (economic) voting. Developed from an early debate within political science about voter motivation, the modern analysis of economic voting concentrates on the effect of macroeconomic outcomes on the popularity (or vote share) of government. ${ }^{4}$ While the literature overwhelmingly supports the hypothesis that governments are held responsible for economic outcomes, recent analyses emphasized the way political institutions influence this relationship. In widely cited paper, Powell and Whitten (1993) find evidence for the 'clarity-of-responsibility hypothesis'. According to this hypothesis, governments are punished for bad economic outcomes more severely if the assignment of responsibility for government policy is

\footnotetext{
${ }^{3}$ Beside the moral-hazard aspect, some analyses introduced an adverse-selection element to the analysis of political accountability (see Banks and Sundaram 1993; Besley and Case 1995; Fearon 1999).

${ }^{4}$ Nannestad and Paldam (1994) provide a survey of the field while the volume edited by Norpoth, Lewis-Beck and Lafay (1991) gives account of many aspects of the literature in more detail.
} 
clearer; that is, in the absence of strong bicameral opposition, in the absence of a strong committee system in the legislature and, particularly relevant in our context, in the case of one-party majority government - as opposed to coalitions. Complementary to this finding, Anderson (1995, Ch. 6) finds in a comparative study of five European democracies that economic conditions shift voter support not only between government and opposition, but also among coalition partners. By investigating theoretically the possibility of voters to reward or punish coalition governments, the present paper intends to contribute to this literature.

The next section analyzes the accountability of a coalition government in the presence of an electoral alternative. Section 3 turns to the case where political accountability is problematic: the case of unity government. Section 4 concludes.

\section{Accountability of electoral blocs}

Consider an economy with an incumbent government $L$, an opponent $R$ (whose role, as usual in electoral accountability models, is perfectly passive) and a continuum of identical voters, represented by voter $I$. The incumbent government $L$ consists of two decision makers (or 'factions'), $M$ and $N$, thus it will be called an 'electoral bloc'.

Each faction in the incumbent government chooses a (non-negative) effort $e_{i} \in \Re_{+}, i \in\{M, N\}$, simultaneously and non-cooperatively. Voters can observe only the sum of efforts, $e=e_{M}+e_{N}$. Effort is beneficial for voters; their payoff $w$ is given as $w=e$. After $e$ becomes public, elections are held, where the incumbent bloc $L$ is facing an opponent $R$. Voters are indifferent between the electoral blocs at the election stage.

The electoral bloc winning the election receives a rent of value $v$. If the incumbent bloc remains in power, the factions share the rent according to exogenously given proportions $\alpha_{i}, i \in\{M, N\}$ with $\alpha_{i} \geqslant 0$ and $\sum \alpha_{i}=1$. Specifically, the payoff of faction $i, i=\{M, N\}$ is given as

$$
u_{i}=\left\{\begin{array}{cc}
\alpha_{i} v-e_{i} & \text { if } L \text { reelected } \\
-e_{i} & \text { else }
\end{array} .\right.
$$

At the beginning of the game, voters coordinate on a voting strategy. We consider the following class of voter strategies: The representative voter $I$ will vote for electoral bloc $L$ if $e \geqslant \bar{e}, \bar{e} \in \Re_{+}$, otherwise she will vote for bloc $R$. Thus, a strategy is given by the value of $\bar{e}$. Such a strategy is sometimes referred to as a 'simple retrospective voting rule' (e.g., Persson et al. 1997).

The sequence of events is as follows: (1) The voters announce a voting strategy for reelecting the incumbent electoral bloc. (2) The factions choose their respective efforts $e_{i}, i \in\{M, N\}$. The sum of efforts $e$ is observed by the voters. (3) Elections take place. The newly elected government earns the rents from office and the game ends.

Since, at the election stage, voters are indifferent between the electoral blocs, it is weakly optimal for them to follow their announced voting strategy, whatever it was. Therefore, it is reasonable to 
concentrate on subgame-perfect equilibria (SPE), where politicians expect voters to execute their announced voting strategy, and voters indeed do so. This allows us to identify the SPE that are optimal from the point of view of the voters, since their announcement is the first move. ${ }^{5}$ In this way, as Persson et al. (1997) point out, we analyze the 'potential' of electoral accountability in different institutional settings, that is, in different constellations of coalition politics.

Proposition 1 In equilibrium, voters reelect the incumbent electoral bloc $L$ if and only if $e \geqslant \bar{e}$, $\bar{e}=v$. The factions of the incumbent electoral bloc put forward an effort $e_{i}=\alpha_{i} v$ for $i=\{M, N\}$, so that $e=\bar{e}$.

Proof. We solve the game backwards. Since voters are indifferent between the electoral blocs at the election stage, it is (weakly) optimal for them to execute their announced voting strategy, whatever that is. We can now turn to the effort stage. Taking effort $e_{j}, j \in\{M, N\}$ as given, faction $i(i \in\{M, N\}, i \neq j)$ compares two relevant alternatives: exerting just enough effort to satisfy the voters or no effort at all. Satisfying the voters is optimal if $\alpha_{i} v-\left(\bar{e}-e_{j}\right) \geqslant 0$ which is equivalent to the condition $\alpha_{i} v \geqslant \bar{e}-e_{j}$. This expression is an incentive constraint: faction $i$ will not exert more effort than $\alpha_{i} v$ to gain reelection. The sum of efforts can thus never exceed $v$ in equilibrium. If, however, voters set $\bar{e}=v$, it is an equilibrium that factions set $e_{i}=\alpha_{i} v$, $i=\{M, N\}$, since their incentive constraints are just binding.

Proposition 1 shows that in a simple political accountability game, voters can extract the full rent from the incumbent government, even if it consists of multiple decision makers (factions). In other words, coalition governments can be held accountable. The result is closely related to Theorem 2 of Holmstrom (1982). Elections provide here a particular type of contract (a discreet team bonus) between the voter (principal) and the incumbent factions (agents). This is, however, exactly the type of contract that solves the free-rider problem of teams in the analysis of Holmstrom.

The result does not depend on the number of factions that constitute the incumbent electoral bloc. What is crucial, however, is the presence of an electoral alternative to the incumbent government. The ability to 'reward' or 'punish' the government as a whole allows the voters to give appropriate team incentives to the incumbent factions.

\section{Accountability of the unity government}

As the analysis of the previous section shows, voters can always provide appropriate collective incentives for the government as long as there is an electoral alternative. Accountability becomes problematic if it is certain that (at least) one of the governing parties stays in power after the

\footnotetext{
${ }^{5}$ Other SPE can be supported by less plausible beliefs on the politicians' side. For instance, there exists a SPE where politicians expect never to be reelected whatever the announced voting strategy was. Thus, they exert no effort. Since voters expect never to see positive effort, they cannot do better than choosing strategy 'never reelect the incumbent'.
} 
elections, a description corresponding to the real-life government form that is often called a 'unity government' or, in other countries, a 'Grand Coalition.' This case is modeled here as a situation without opposition. The only thing voters can do is to choose between the government parties. ${ }^{6}$

Two further conditions are necessary for political accountability not to work in our framework. The first condition is that the effort of the government parties cannot be disentangled by the voters. They observe only the sum of efforts, that is, only one measure of government performance. This condition would not hold in a framework where voters could assign the responsibility for every issue (or, more generally, every action) to one of the coalition parties in the spirit of Laver and Shepsle (1990). However, there are reasons why inseparability of responsibility is a plausible assumption in our context. The first reason is that the most prominent policy decisions require agreement among coalition partners to pass legislation. Moreover, many outcomes of interest (like the state of the economy in general or the level of government spending) are influenced by many factors; responsibility for them cannot be assigned to a single policy act or a single agent.

The second condition for accountability not to work is the possibility of 'sabotage', defined here as costly effort reducing government performance. Neither of these conditions represents a departure from the framework presented in the analysis of electoral blocs. Clearly, none of the factions had an incentive to engage in sabotage in that context. Further discussion of the importance of these conditions is provided after the main results.

Consider an economy with two office-motivated parties, $L$ and $R$, both in government at the beginning of the game. The parties choose effort $e_{i} \in \Re, i \in\{L, R\}$ simultaneously and noncooperatively. Negative effort is possible, but is costly: the cost of effort is equal to $\left|e_{i}\right|$. There is a continuum of identical voters. The voters observe only the sum of efforts, $e=e_{L}+e_{R}$. The voters' utility $w$ is given by $w=e$. After $e$ becomes public, elections are held, where voters can choose between the incumbent parties $L$ and $R$. The representative voter $I$ wants to induce a high effort by the government parties with her voting behavior, and is inherently indifferent between the two parties at the election stage. The party that wins the election receives a rent of value $v_{i}, i \in\{L, R\}$. Note that in this case, parties may have different valuations of winning (equal valuations will be discussed as a special case). Party $i$ 's $(i \in\{L, R\})$ payoff is thus:

$$
u_{i}=\left\{\begin{array}{cc}
v_{i}-\left|e_{i}\right| & \text { if } i \text { elected } \\
-\left|e_{i}\right| & \text { else }
\end{array} .\right.
$$

The sequence of events is as follows: (1) The voters announce a voting strategy (see below).

\footnotetext{
${ }^{6}$ In the formulation presented here, the unity government cannot be an outcome of the election. This inconsistency can be remedied, without changing the qualitative results of the analysis, in a more complex voting game. Such a voting game would involve an additional extreme party and a division of voters to 'partisan' and 'swing' voters, where swing voters decide the elections with a certain probability strictly between zero and one. Swing voters would have the same strategy space as the voters in the present analysis; they would never consider to vote for the extreme party. In such a world, the unity government is a possible outcome of the election, but the equilibria of the accountability game would remain qualitatively unchanged. This extended voting game was described in an earlier version of this paper and is available on request.
} 
(2) The parties choose their respective efforts $e_{i}, i=\{L, R\}$. The sum of efforts $e$ is observed by the voters. (3) Elections take place. The newly elected government earns the rents from office and the game ends.

We consider the following class of simple retrospective voter strategies: Representative voter $I$ will vote for party $i, i \in\{L, R\}$, if and only if $e \geqslant \bar{e}, \bar{e} \in \Re$. Otherwise she will vote for party $j \in\{L, R\}, j \neq i$. In this way, a strategy is given by a pair $\{i, \bar{e}\}$. Note that the payoff of party $j$ is strictly monotonically decreasing in effort. Beside the fact that effort is costly, the higher the government effort the less probable that party $j$ wins the elections. On the other hand, the payoff of party $i$ has a discrete positive jump in effort (when $e_{j}$ is kept constant). Thus we can say that voter strategy gives 'positive incentives' to party $i$ and 'negative incentives' to party $j$. This means that if sabotage (costly negative effort) is possible, party $j$ has an incentive to employ it. Therefore, we expect $e_{i} \geqslant 0$ and $e_{j} \leqslant 0$. To avoid confusion about the signs, let us define $s_{j} \equiv-$ $e_{j} \geqslant 0$ as the (non-negative) sabotage of party $j$.

This game is structurally identical to a particular type of first-price all-pay auction with the two parties as 'bidders.' The 'bids' are the efforts $e_{i}$ and $s_{j}$. The cost of effort cannot be recovered. The representative voter plays the role of an 'auctioneer.' The 'prize' the parties are fighting for is the rent they receive in case of reelection. Party $i$ wins the prize if and only if $e_{i} \geqslant \bar{e}+s_{j}$. The last expression entails a departure from the standard all-pay auction. By setting $\bar{e}$, voters can advantage one of the parties and handicap the other. A model with this structure, a class of contests with a 'head-start advantage,' has been analyzed by Konrad (2002). As a difference to that paper, the voter's (auctioneer's) problem plays a major role in our setting, as the 'head-start advantage' here is not of technical, but rather of strategic, nature. (For this reason we will also use the term 'handicap' beside 'threshold level of effort' to refer to $\bar{e}$.) The objective of the voters is also unusual. Since the effort of one party benefits the representative voter, but the effort of the other harms her, her objective will be to maximize the expected difference in both efforts. Formally, the voters' problem is

$$
\max _{\bar{e}} E(e) ; \text { with } E(e)=E\left(e_{L}+e_{R}\right)=E\left(e_{i}-s_{j}\right) .
$$

To solve the game we apply the equilibrium selection criteria discussed in Section 2. The parties expect voters to execute their announced voting strategy, and voters indeed do so, since it is weakly optimal for them. Each point in the voters' strategy space implements an all-pay auction with a handicap. The voters choose optimally from a restricted set of strategies.

Two points are worth noting about the equilibrium. First, although one party exerts positive effort and the other exerts negative effort (sabotage), the voters do not want to 'punish' the saboteur. Voters know that party behavior is induced by the voters' electoral strategy; that strategy in turn is designed to maximize voters' expected payoff. Ultimately, the emergence of sabotage is the price voters have to pay for being able to give incentives at all; to avoid sabotage, they would have to renounce from any incentive effect (e.g., by not making their voting behavior 
conditional on government performance). It would also mean that they earn a zero payoff with certainty.

Second, voters can choose which party they make responsible for the government's performance. Choosing optimally, as we will see, voters will give positive incentives to the party with the higher valuation (and choose an appropriate performance threshold). The fact that voters can choose which party to make responsible for the outcome may seem unrealistic in the context of the application. In a real-life example, it could be that the prime minister's party is automatically viewed as being responsible for the outcome. But in that case the coalition partner will have an incentive for sabotage; and the resulting equilibrium would have the same structure as described here. In summary, both of these aspects might be 'unrealistic' in the context of the real-world political application. But replacing them with more realistic assumptions would not alleviate the accountability problem of the 'unity government'; if anything it would make it worse by restricting the voters' set of possible strategies.

Proposition 2 Let us assume, without loss of generality, that $v_{R} \geqslant v_{L}$. In equilibrium, voters give their vote to party $R$ if $e \geqslant \bar{e}$, and $L$ otherwise; the optimally chosen reservation utility is $\bar{e}=\max \left\{\frac{v_{R} v_{L}}{v_{R}+v_{L}}, v_{R}-v_{L}\right\}$.

Further, parties choose mixed strategies to determine their effort levels:

(i) If $\frac{v_{R} v_{L}}{v_{R}+v_{L}}>v_{R}-v_{L}$, then the unique mixed-strategy equilibrium of the effort subgame is described by following cumulative distribution functions:

$$
\begin{gathered}
H_{L}\left(s_{L}\right)=\left\{\begin{array}{cc}
0 & \text { for } s_{L}<0 \\
\frac{\bar{e}}{v_{R}}+\frac{s_{L}}{v_{R}} & \text { for } 0 \leqslant s_{L} \leqslant v_{R}-\bar{e} \\
1 & \text { for } s_{L}>v_{R}-\bar{e}
\end{array}\right. \\
H_{R}\left(e_{R}\right)=\left\{\begin{array}{cc}
0 & \text { for } e_{R}<0 \\
\frac{\bar{e}-\left(v_{R}-v_{L}\right)}{v_{L}} & \text { for } 0 \leqslant e_{R}<\bar{e} \\
\left.11-\frac{v_{R}}{v_{L}}\right]+\frac{e_{R}}{v_{L}} & \text { for } \bar{e} \leqslant e_{R} \leqslant v_{R} \\
1 & \text { for } e_{R}>v_{R}
\end{array}\right.
\end{gathered}
$$

(ii) If $\frac{v_{R} v_{L}}{v_{R}+v_{L}} \leqslant v_{R}-v_{L}$, then the unique mixed-strategy equilibrium of the effort subgame is described by following cumulative distribution functions:

$$
\begin{gathered}
H_{L}\left(s_{L}\right)=\left\{\begin{array}{cc}
0 & \text { for } s_{L}<0 \\
{\left[1-\frac{v_{L}}{v_{R}}\right]+\frac{s_{L}}{v_{R}}} & \text { for } 0 \leqslant s_{L} \leqslant v_{L} \\
1 & \text { for } s_{L}>v_{L}
\end{array}\right. \\
H_{R}\left(e_{R}\right)=\left\{\begin{array}{cc}
0 & \text { for } e_{R}<\bar{e} \\
\frac{e_{R}}{v_{L}}-\frac{\bar{e}}{v_{L}} & \text { for } \bar{e} \leqslant e_{R} \leqslant v_{L}+\bar{e} \\
1 & \text { for } e_{R}>v_{L}+\bar{e}
\end{array} .\right.
\end{gathered}
$$


Proof. See the Appendix.

For the case where $v_{R}=v_{L}=v$, the limit of the Proposition can be applied. The voters can choose arbitrarily to which of both parties they give positive incentives. The condition of case (i) is fulfilled, thus the optimally chosen threshold level of effort (or handicap) is $\bar{e}=\frac{v}{2}$.

The following example may give an intuition for Proposition 2. Let us assume that $v_{R}>v_{L}$. We will solve for the equilibrium party behavior for the case when voters in the first stage chose a retrospective voting strategy described by the pair $\{R, \bar{e}\}$ with $\bar{e} \geqslant v_{R}-v_{L}$. Voters in this example choose to give party $R$ positive incentives and vote for it if $e \geqslant \bar{e}$ and for party $L$ otherwise.

We can write the expected payoffs of the parties as follows: $u_{R}=\operatorname{Pr}\left(e_{R} \geqslant \bar{e}+s_{L}\right) v_{R}-e_{R}$ and $u_{L}=\left[1-\operatorname{Pr}\left(e_{R} \geqslant \bar{e}+s_{L}\right)\right] v_{L}-s_{L}$. As it is established in the analysis of all-pay auctions, this type of game has no equilibrium in pure strategies. We will follow the literature to find the mixed strategy equilibrium. ${ }^{7}$

First, no party will choose a 'bid' (that is, effort or sabotage) that is higher than its valuation, since such a choice gives a negative payoff with certainty. Also, no party will bid below zero, since such a bid is costly and reduces the party's chances of winning compared to bidding zero. Party $R$ thus loses with certainty for any bid $e_{R}<\bar{e}$, since such a bid loses against the smallest possible bid of the opponent, $s_{L}=0$. Therefore, $R$ will not put forward any positive bid below $\bar{e}$. On the other hand, party $L$ can secure the prize with a bid of $s_{L}=v_{R}-\bar{e}$, earning a secure payoff of $v_{L}-v_{R}+\bar{e}$. (This payoff is positive, since we are considering the case where $\bar{e} \geqslant v_{R}-v_{L}$.) Thus we expect that $R$ will randomize on the interval $\left[\bar{e}, v_{R}\right]$, earning zero in expectation and that $L$ will randomize over $\left[0, v_{R}-\bar{e}\right]$ earning an expected payoff of $v_{L}-v_{R}+\bar{e}$. In this case, the 'handicap' $\bar{e}$ is large enough to turn around the 'ranking' of the players, letting the originally 'stronger' player become the 'weaker' one.

As all actions that a player randomizes over have to give the same expected payoff, we can reach the following equation for party $L$ 's actions $s_{L}$.

$$
H_{R}\left(s_{L}+\bar{e}\right) v_{L}-s_{L}=v_{L}-v_{R}+\bar{e}
$$

From this we can solve for $H_{R}\left(e_{R}\right)$, the cumulative distribution function (c.d.f.) of $R$ 's bids. Since the previous equation has to hold for any $s_{L} \in\left[0, v_{R}-\bar{e}\right]$, the following equation has to hold for any $e_{R}=s_{L}+\bar{e}, e_{R} \in\left[\bar{e}, v_{R}\right]$ :

$$
H_{R}\left(e_{R}\right)=\left[1-\frac{v_{R}}{v_{L}}\right]+\frac{e_{R}}{v_{L}} .
$$

Note that $R$ 's bid distribution function has a mass point on zero (since we know he will not bid between zero and $\bar{e}$ ). Similarly, the equation that describes the expected payoff of $R$ 's actions, $H_{L}\left(e_{R}-\bar{e}\right) v_{R}-e_{R}=0$, helps us find the solution for $L$ 's bid distribution function $H_{L}\left(s_{L}\right)$ for $s_{L} \in\left[0, v_{R}-\bar{e}\right]$.

$$
H_{L}\left(s_{L}\right)=\frac{\bar{e}}{v_{R}}+\frac{s_{L}}{v_{R}}
$$

\footnotetext{
${ }^{7}$ See, for example, Hirshleifer and Riley (1992, Section 10.1.2) and Konrad (2002). The uniqueness of this equilibrium can be shown analogously to the uniqueness proof of Baye et al. (1996).
} 


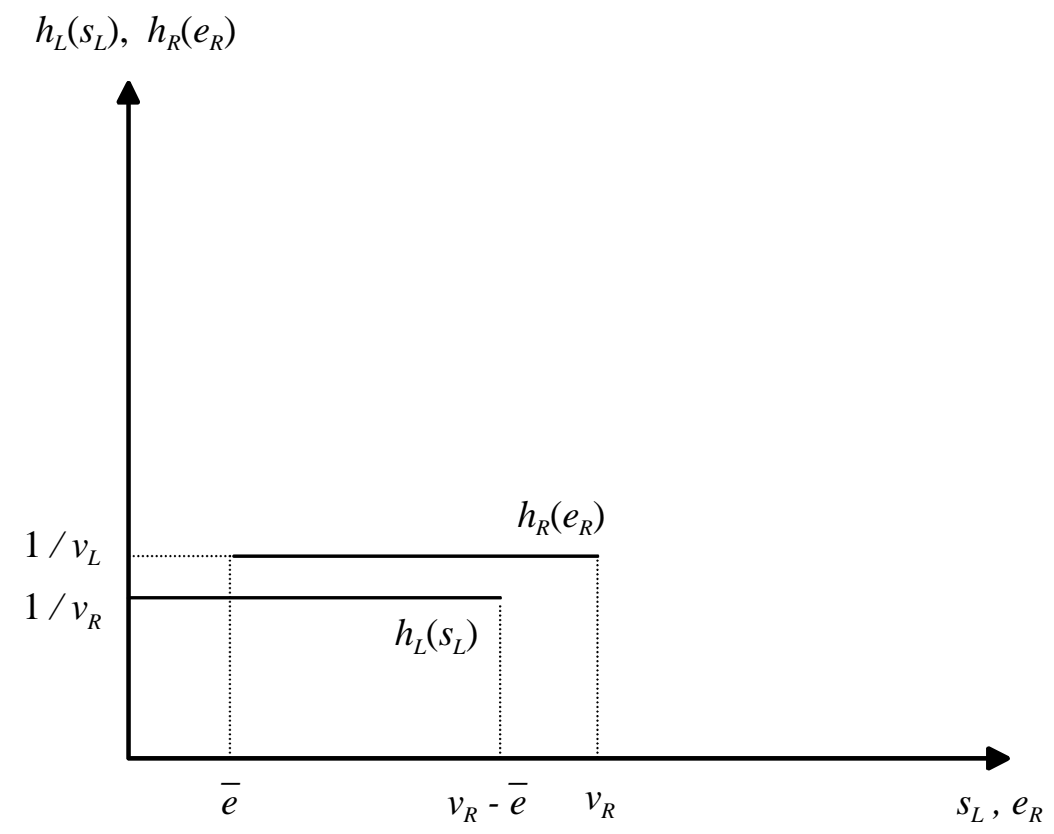

Figure 1: Density functions of party effort in mixed-strategy equilibrium. (Mass points on zero not displayed.)

Thus L's bid function also has a mass point on zero. The bid distributions constitute an equilibrium, since they were constructed so. Further, the distribution functions allow us to calculate the expected payoff of the voters in equilibrium.

Figure 1, depicting the density functions of party effort and sabotage, gives an intuition about the trade-off the voters are facing. A higher handicap $\bar{e}$ reduces $R$ 's expected effort because it raises the threshold below which $R$ does not bid. In effect, the lowest bids of $R$ are turned to zero-bids and the rest is unchanged. At the same time, a higher handicap $\bar{e}$ reduces $L$ 's expected sabotage as well; but it is the highest-sabotage bids that are removed. Starting from $\bar{e}=v_{R}-v_{L}$ as a reference point, a small increase in the reservation utility reduces expected sabotage more than expected effort, as long as $v_{R}-v_{L}$ is small enough. Thus, in that case, the optimal handicap is expected to more than compensate for the difference in valuations between the parties. In other words, if the party with the higher valuation is given positive incentives, it will at the same time be severely handicapped in the voters' optimum.

From Proposition 2 we can calculate voters' payoff as

$$
w_{I}=\left\{\begin{array}{cl}
\frac{v_{R}^{3}}{2 v_{L}\left(v_{R}+v_{L}\right)} & \text { if } \bar{e}=\frac{v_{R} v_{L}}{v_{R}+v_{L}}>v_{R}-v_{L} \\
\frac{\left(v_{R}-v_{L}\right)\left(v_{L}+2 v_{R}\right)}{2 v_{R}} & \text { if } \bar{e}=v_{R}-v_{L}>\frac{v_{R} v_{L}}{v_{R}+v_{L}}
\end{array}\right.
$$

The first line simplifies to $w_{I}=\frac{v}{4}$ if $v_{R}=v_{L}=v$. Thus, voters get a positive expected payoff even facing a unity government and the possibility of sabotage. Voter payoff is, however, dramatically reduced as compared to the case when an opposition is present. (There, as we saw, voters can 
receive the full rent $v$.) This is true because the positive effort of the one party is lower than valuation $v$ with probability 1 , while the other party engages in sabotage activity.

It remains to discuss the importance of the two assumptions mentioned above: the possibility of sabotage and the non-observability of individual party effort. It is easy to see that, if sabotage is not possible, voters could give positive incentives to the party with the higher valuation without inducing outright conflict. In that case, again, full rent can be extracted from the party. If, on the other hand, the effort of each party were observed, voters would have no reason to condition their voting strategy on the sum of efforts. Instead, they could induce a 'beneficial' tournament announcing that the party with the higher effort will gain their support.

\section{Conclusion}

This paper analyzed the political accountability of coalitions as a problem of moral hazard in teams. It is shown that a coalition government can be held accountable as long as there is an electoral alternative. Voters can always threaten not to reelect the government, which gives the appropriate team incentives to the government.

The accountability of coalition governments becomes problematic if the voters have no electoral alternative. In this case it is certain that (at least) one of the incumbent parties remain in power after the next election. Voters cannot give appropriate team incentives to the government, but only choose between the incumbent parties. It was shown that even in this situation, voters can induce a positive expected government performance by making one coalition party responsible for the outcome. This voting strategy creates a conflict among the government parties, making one party interested in reducing government output. The paper solves for the optimal strategy of the voters as 'designers' of the resulting contest between the government parties.

The theoretical description of a coalition government with no electoral alternative corresponds to the real-life examples of 'unity government' or, as it is known in some countries, 'Grand Coalition.' Such coalitions of the main centre-left and centre-right parties typically form in political systems with Proportional Representation (PR) in the presence of extreme parties. Thus, the analysis points at a specific source of accountability deficit in PR systems.

The analysis also provides a counter-argument to notions of 'coalition inefficiency' often cited in empirical analyses. Such arguments do not take into account the role of elections. Even if coalitions do face collective action problems, they also have an incentive to overcome them if their reelection probability decreases after inefficient outcomes. The possibility of (no) reelection gives the politicians incentives to act in the citizens' interest.

As an implication for empirical research, it appears that the number of parties included in a government coalition (the variable universally used in empirical work to control for blurred responsibility) may not be the most informative variable. The political constellation in which a (coalition) government operates should play a crucial role. Specifically, it could be useful to identify 
the weight of extreme parties in the legislature, since this shows ultimately whether there is a real electoral alternative to the government. Information on the electoral margin of government may also indicate the presence of a 'unity government.'

This study did not consider aspects of coalition formation and breakup. The inclusion of this aspect would, however, not affect our results. If, for example, a political faction leaves an electoral bloc, voters have still no incentive to change their strategy in the elections: voting for the incumbent bloc after good outcomes and for the opposition after bad ones. Similarly, an additional coalition formation stage at the beginning of the game would not affect the main driving forces of the analysis: once a governing coalition is in place, the actions of coalition partners are shaped solely by the incentives that voters give them.

A possible path of future research is to analyze the problems of coalition government and political accountability in a more detailed public finance framework. This could allow us to introduce more explanatory factors to analyze the question under what circumstances the 'common pool' effect is (un)likely to emerge in coalition governments.

\section{A Appendix}

\section{A.1 Proof of Proposition 2}

We assumed, without loss of generality, that $v_{R} \geqslant v_{L}$. We can divide the representative voter $I$ 's strategy space $i, \bar{e} \in R, L \times \Re$ into six ranges. These differ along two dimensions: 1) whether the voters give positive incentives to the party with the higher valuation (whether $i=R$ ) or to the party with the lower valuation $(i=L)$; and 2) in which of three intervals the reservation utility $\bar{e}$ is chosen. The reason for separating exactly these ranges is that the resulting all-pay auction has a different mixed-strategy equilibrium in each of them. In each strategy range we first characterize equilibrium party behavior for a given $\bar{e}$ and search for the voter's optimal choice of $\bar{e}$ within the given range. Then we will be able to make a global statement about $I^{\prime}$ s optimal strategy.

Range 1: Give positive incentives to the party with the higher valuation and handicap it slightly. Suppose voter $I$ 's strategy is given by the pair $\{R, \bar{e}\}$ with $v_{R}-v_{L} \geqslant \bar{e} \geqslant 0$. The c.d.f. of the parties' equilibrium bid functions are as follows (to save space, we will suppress intervals where the c.d.f. of the bid functions is 0 or 1 ):

$$
\begin{aligned}
& H_{L}\left(s_{L}\right)=\left[1-\frac{v_{L}}{v_{R}}\right]+\frac{s_{L}}{v_{R}} \text { for } 0 \leqslant s_{L} \leqslant v_{L} \\
& H_{R}\left(e_{R}\right)=\frac{e_{R}}{v_{L}}-\frac{\bar{e}}{v_{L}} \text { for } \bar{e} \leqslant e_{R} \leqslant v_{L}+\bar{e}
\end{aligned}
$$

To check that this constitutes an equilibrium, note that $L$ has a negative payoff for all bids below 0 or above his valuation $v_{L}$. For any bid $s_{L}$ between these values $L$ 's payoff is $H_{R}\left(s_{L}+\bar{e}\right) v_{L}-s_{L}$ 
which is equal to zero given the supposed form of $H_{R}$. On the other hand, the payoff of $R$ for any bid $e_{R}$ between $\bar{e}$ and $v_{L}+\bar{e}$ is $H_{L}\left(e_{R}-\bar{e}\right) v_{R}-e_{R}$ which, given the supposed form of $H_{L}$, is equal to $v_{R}-v_{L}-\bar{e}$. It is easy to see that any bid outside this range gives an inferior payoff. Uniqueness of this equilibrium can be shown along the lines of Baye et al. (1996).

The representative voter, seeking to choose the best $\bar{e}$ in the relevant interval $v_{R}-v_{L} \geqslant \bar{e} \geqslant 0$, wants to maximize $e=e_{R}-s_{L}$. She notes that her choice does not affect $L$ 's optimal strategy, but that a higher $\bar{e}$ translates one-to-one to higher effort $e_{R}$ (in a stochastic sense). Therefore the voter's best option is to choose the upper limit of this interval, that is, $\bar{e}=v_{R}-v_{L}$. Her expected payoff is then

$$
E\left[e_{R}-s_{L}\right]=\frac{v_{L}^{2}\left(v_{R}-v_{L}\right)}{2 v_{R} v_{L}}+\bar{e}=\frac{\left(v_{R}-v_{L}\right)\left(v_{L}+2 v_{R}\right)}{2 v_{R}}>0 .
$$

Range 2: Give positive incentives to the party with the higher valuation while handicapping it strongly. Suppose voter I's strategy is given by the pair $\{R, \bar{e}\}$ with $\bar{e} \geqslant$ $v_{R}-v_{L} \geqslant 0$. Then, the c.d.f. of the parties' equilibrium bid functions (identical to the example in the main text) are given by:

$$
\begin{gathered}
H_{L}\left(s_{L}\right)=\frac{\bar{e}}{v_{R}}+\frac{s_{L}}{v_{R}} \text { for } 0 \leqslant s_{L} \leqslant v_{R}-\bar{e} \\
H_{R}\left(e_{R}\right)=\left\{\begin{array}{cc}
\frac{\bar{e}-\left(v_{R}-v_{L}\right)}{v_{L}} & \text { for } 0 \leqslant e_{R}<\bar{e} \\
{\left[1-\frac{v_{R}}{v_{L}}\right]+\frac{e_{R}}{v_{L}}} & \text { for } \bar{e} \leqslant e_{R} \leqslant v_{R}
\end{array}\right.
\end{gathered}
$$

Following the same steps as in Range 1, it can be shown that this constitutes an equilibrium. Now we can turn to the voters' problem.

$$
\begin{gathered}
\max _{\bar{e}} E\left[e_{R}-s_{L}\right] \text { s.t. } \bar{e} \geqslant v_{R}-v_{L} \geqslant 0 . \\
E\left[e_{R}-s_{L}\right]=E\left[e_{R}\right]-E\left[s_{L}\right]=\int_{\bar{e}}^{v_{R}} e_{R} h_{R}\left(e_{R}\right) d e_{R}-\int_{0}^{v_{R}-\bar{e}} s_{L} h_{L}\left(s_{L}\right) d s_{L} .
\end{gathered}
$$

Here, the first equation comes from the fact that the parties randomize independently from one another, the second uses the usual definition of the expected value of a continuous variable, where mass points at zero can be suppressed. Note that the bid densities are constant on the relevant intervals. Now it is easy to evaluate the integrals to get

$$
E\left[e_{R}-s_{L}\right]=\frac{v_{R}^{2}\left(v_{R}-v_{L}\right)}{2 v_{R} v_{L}}+\bar{e}-\frac{v_{R}+v_{L}}{2 v_{R} v_{L}} \bar{e}^{2} .
$$

We get the first-order condition by differentiating this last expression with respect to $\bar{e}$ and equating the result to zero. This gives us $\bar{e}=\frac{v_{R} v_{L}}{v_{R}+v_{L}}$. The second-order condition is clearly fulfilled. But we have to make sure that the optimum lies in the considered range $\bar{e} \geqslant v_{R}-v_{L}$. This is the case if $v_{R} \leqslant \frac{1+\sqrt{5}}{2} v_{L}$. For $v_{R}>\frac{1+\sqrt{5}}{2} v_{L}$ we have a corner solution $\bar{e}=v_{R}-v_{L}>\frac{v_{R} v_{L}}{v_{R}+v_{L}}$. To summarize, in this range, voter I's optimal choice for the 'handicap' $\bar{e}$ is given by

$$
\bar{e}=\max \left\{\frac{v_{R} v_{L}}{v_{R}+v_{L}}, v_{R}-v_{L}\right\} .
$$


Range 3: Give positive incentives to the party with the higher valuation and give it a head-start advantage. Suppose voter I's strategy is given by the pair $\{R, \bar{e}\}$ with $v_{R}-v_{L} \geqslant 0 \geqslant \bar{e}$. The equilibrium bid functions are

$$
\begin{gathered}
H_{L}\left(s_{L}\right)=\left\{\begin{array}{cc}
\frac{v_{R}-v_{L}-\bar{e}}{v_{R}} & \text { for } 0 \leqslant s_{L}<-\bar{e} \\
{\left[1-\frac{v_{L}}{v_{R}}\right]+\frac{s_{L}}{v_{R}}} & \text { for }-\bar{e} \leqslant s_{L} \leqslant v_{L}
\end{array}\right. \\
H_{R}\left(e_{R}\right)=\frac{e_{R}}{v_{L}}-\frac{\bar{e}}{v_{L}} \text { for } 0 \leqslant e_{R}<v_{L}-\bar{e}
\end{gathered}
$$

The objective function of the voter is

$$
E\left[e_{R}-s_{L}\right]=\frac{v_{L}^{2}\left(v_{R}-v_{L}\right)}{2 v_{R} v_{L}}+\bar{e}+\frac{v_{R}+v_{L}}{2 v_{R} v_{L}} \bar{e}^{2} .
$$

This expression describes a convex parabola. On the one end of the relevant range, at $\bar{e}=0$, the pay-off is positive, then it decreases below zero as $\bar{e}$ decreases only to start to rise again, reaching zero at $\bar{e}=-v_{L}$. For higher performance thresholds voter payoff is constant zero, since the outcome of the game is trivial: no party exerts effort as $L$ cannot win. Thus, the optimal 'head-start advantage' in this range is $\bar{e}=0$.

Range 4: Give positive incentives to the party with the lower valuation and give it a slight head-start advantage. Suppose voter I's strategy is given by the pair $\{L, \bar{e}\}$ with $v_{L}-v_{R} \leqslant \bar{e} \leqslant 0$. Then, the equilibrium bid functions resemble those found in Range 1 (Read $-\bar{e}$ for $\bar{e}$; exchange $s_{i}$ for $e_{i}$ and vice versa). Also, just as in Range 1, party $L$ 's optimal strategy is not affected by the choice of handicap. Voter payoff is

$$
E\left[e_{L}-s_{R}\right]=\frac{v_{L}^{2}\left(v_{L}-v_{R}\right)}{2 v_{R} v_{L}}+\bar{e} .
$$

This expression is monotone increasing in $\bar{e}$, so the optimal choice is given by the upper corner $\bar{e}=0$. Note that voter payoff is negative at this point.

Range 5: Give positive incentives to the party with the lower valuation and give it a significant head-start advantage. Suppose voter I's strategy is given by the pair $\{L, \bar{e}\}$ with $\bar{e} \leqslant v_{L}-v_{R} \leqslant 0$. The equilibrium bid functions resemble those found in Range 2 . The objective function of the voters is

$$
E\left[e_{L}-s_{R}\right]=\frac{v_{R}^{2}\left(v_{L}-v_{R}\right)}{2 v_{R} v_{L}}+\bar{e}+\frac{v_{R}+v_{L}}{2 v_{R} v_{L}} \bar{e}^{2} .
$$

This is another case where the objective is a convex parabola. Possibilities for the optimum are $\bar{e}=v_{L}-v_{R}$ and $\bar{e}=-v_{R}$. Calculating the payoff for $\bar{e}=v_{L}-v_{R}$, we find a negative payoff

$$
E\left[e_{L}-s_{R}\right]=\frac{\left(v_{L}-v_{R}\right)\left(v_{L}+2 v_{R}\right)}{2 v_{R}}<0
$$


At the same time, $\bar{e}=-v_{R}$ (and any choice below that) implements a trivial auction where bids equal zero and $L$ always wins. This option delivers zero payoff to $I$ and is therefore optimal within this range.

\section{Range 6: Give positive incentives to the party with the lower valuation and hand-} icap it. Suppose voter I's strategy is given by the pair $\{L, \bar{e}\}$ with $v_{L}-v_{R} \leqslant 0 \leqslant \bar{e}$. The bid functions resemble those in found in Range 3. The expected payoff of the voters is

$$
E\left[e_{L}-s_{R}\right]=\frac{v_{L}^{2}\left(v_{L}-v_{R}\right)}{2 v_{R} v_{L}}+\bar{e}-\frac{v_{R}+v_{L}}{2 v_{R} v_{L}} \bar{e}^{2} .
$$

Note that this objective is identical to the one found in Range 2 up to the constant. (Note also that the constant here is negative while it is positive for Range 2.) Therefore, the optimal handicap is the same as there, $\bar{e}=\frac{v_{R} v_{L}}{v_{R}+v_{L}}$ (here unconstrained). The voter's payoff is compared below.

The global optimum. After calculating the optimum in each of these ranges we are to rank these (restricted) optima. We will show that the Range-2-optimum represents a global optimum, which proves the Proposition.

First note that Ranges 4 and 5 cannot produce a positive payoff to $I$; they are thus strictly inferior to Range 1.

Second, note that all strategy ranges are defined such as to include interval limits. This is useful because Range 3 has a corner solution which is an available option in adjacent Range 1. Similarly, Range 1 exhibits a corner solution which is an available option in adjacent Range 2. Therefore, the optimal strategy in Range 2 represents the optimum over Ranges 1, 2, and 3, 4 and 5 .

The last step is to show that the optimal strategy in Range 2 is superior to that in Range 6 . Here we have to distinguish to cases.

Case A: $v_{L}<v_{R} \leqslant \frac{1+\sqrt{5}}{2} v_{L}$. Here the optimum in Range 2 is $\bar{e}=\frac{v_{R} v_{L}}{v_{R}+v_{L}}$ just as in Range 6 . We have noted that voter $I$ 's objective differs across the two ranges only by a constant. Evaluated at the same reservation utility $\bar{e}$, voter $I^{\prime}$ s payoff is strictly higher in Range 2.

Case B: $v_{R}>\frac{1+\sqrt{5}}{2} v_{L}$, or, equivalently, $v_{R}-v_{L}>\frac{v_{R} v_{L}}{v_{R}+v_{L}}$. Here, in Range 2 we have a corner solution at $\bar{e}=v_{R}-v_{L}$ giving a payoff of $\frac{\left(v_{R}-v_{L}\right)\left(v_{L}+2 v_{R}\right)}{2 v_{R}}$ to $I$. We can express $I$ 's payoff at the optimum in Range 6 as

$$
\frac{v_{L}^{3}}{2 v_{R}\left(v_{R}+v_{L}\right)}=\frac{v_{R} v_{L}}{v_{R}+v_{L}} \frac{v_{L}^{2}}{2 v_{R}^{2}}<\left(v_{R}-v_{L}\right) \frac{v_{L}^{2}}{2 v_{R}^{2}},
$$

where we used Case B's defining inequality. To show that the optimum in Range 6 is inferior to the one of Range 2, we need

$$
\frac{\left(v_{R}-v_{L}\right) v_{L}^{2}}{2 v_{R}^{2}}<\frac{\left(v_{R}-v_{L}\right)\left(v_{L}+2 v_{R}\right)}{2 v_{R}},
$$

which is fulfilled as 


$$
\frac{v_{L}^{2}}{2 v_{R}^{2}}<\frac{1}{2}<1<\frac{\left(v_{L}+2 v_{R}\right)}{2 v_{R}} .
$$

This completes the proof. 


\section{References}

Anderson, C. (1995). Blaming the government: citizens and the economy in five European democracies. Armonk, NY: M. E. Sharp.

Ashworth, J., Geys, B. \& Heyndels, B. (2005). Government weakness and local public debt development in Flemish municipalities. International Tax and Public Finance, 12, 395-422.

Banks, J. S. \& Sundaram, R. K. (1993). Adverse selection and moral hazard in a repeated elections model. In Barnett, Hinich \& Schofield (Eds.), Political economy: Institutions, competition and representation. Cambridge University Press.

Barro, R. (1973). The control of politicians: An economic model. Public Choice, 14(1), 19-42.

Battaglini, M. (2006). Joint production in teams. Journal of Economic Theory, 130(1), 138-167.

Baye, M., Kovenock, D. \& de Vries, C. (1996). The all-pay auction with complete information. Economic Theory, 8, 291-305.

Besley, T. (2006). Principled agents? The political economy of good government. Oxford: Oxford University Press.

Besley, T. \& Case, A. (1995). Incumbent behavior: vote-seeking, tax-setting, and yardstick competition. American Economic Review, 85(1), 25-45.

Che, Y.-K., \& Yoo, S.-W. (2001). Optimal incentives for teams. American Economic Review, 91(3), $525-541$.

Chen, K.-P. (2003). Sabotage in promotion tournaments. Journal of Law, Economics and Organization, 19, 119-140.

de Haan, J. \& Sturm, J.-E. (1997). Political and economic determinants of OECD budget deficits and government expenditures: A reinvestigation. European Journal of Political Economy, 13, 739750 .

Dewatripont, M. \& Seabright, P. (2006). "Wasteful" public spending and state aid control. Journal of the European Economic Association, 4(2-3), 513-522.

Fearon, J. D., (1999). Electoral accountability and the control of politicians: Selecting good types versus sanctioning poor performance. In Przeworski, Stokes, \& Manin (Eds.), Democracy, accountability and representation. Cambridge University Press.

Ferejohn, J., (1986). Incumbent performance and electoral control. Public Choice, 50, 5-25.

Geys, B., Heyndels, B. \& Vermeir, J. (2006). Explaining the formation of minimal coalitions: Anti-system parties and anti-pact rules. European Journal of Political Research, 45, 957-984. 
Hillman, A. \& Riley, J. (1989). Politically contestable rents and transfers. Economics and Politics, $1,17-40$.

Hirshleifer, J. \& Riley, J. (1992). The analytics of uncertainty and information. Cambridge University Press.

Holmstrom, B. (1982). Moral hazard in teams. The Bell Journal of Economics, 13(2), 324-340.

Illera, R. M. \& Mulas-Granados, C. (2008). What makes fiscal consolidations last? A survival analysis of budget cuts in Europe (1960-2004). Public Choice, 134, 147-161.

Itoh, H. (1991). Incentives to help in multi-agent situations. Econometrica, 59, 611-636.

Konrad, K. A. (2000). Sabotage in rent-seeking contests. Journal of Law, Economics and Organization, 16(1), 155-165.

Konrad, K. A., (2002). Investment in the absence of property rights; The role of incumbency advantages. European Economic Review, 46, 1521-1537.

Laver, M. \& Shepsle, K. A. (1990). Coalitions and cabinet government. American Political Science Review, 84(3), 873-889.

Laver, M. \& Schofield, N. (1990). Multiparty government: The politics of coalition in Europe. Oxford University Press.

Lazear, E. (1989). Pay equality and industrial politics. Journal of Political Economy, 97(3), 561580 .

Maskin, E. \& Tirole, J. (2004). The politician and the judge: accountability in government. American Economic Review, 94(4), 1034-1054.

Mierau, J. O., Jong-A-Pin, R., \& de Haan, J. (2007). Do political variables affect fiscal policy adjustment decisions? New empirical evidence. Public Choice, 133, 297-319.

Münster, J. (2007). Selection tournaments, sabotage, and participation. Journal of Economics and Management Strategy, 16(4), 943-970.

Nannestad, P. and Paldam, M. (1994). The VP function: A survey of the literature on vote and popularity functions after 25 years. Public Choice, 79, 213-245.

Norpoth, H. Lewis-Beck, M. S. \& Lafay, J.-D. (Eds.) (1991). Economics and politics: The calculus of support. Ann Arbor: The University of Michigan Press.

Persson, T., Roland, G. \& Tabellini, G. (1997). Separation of powers and political accountability. Quarterly Journal of Economics, 112 (4), 1163-1202. 
Persson, T. \& Tabellini, G. (2000). Political economics: Explaining economic policy. Cambridge, Mass: MIT Press.

Powell, G. B. \& Whitten, G. D. (1993). A cross-national analysis of economic voting: taking account of the political context. American Journal of Political Science, 37(2), 391-414.

Roubini, N. \& Sachs, J. (1989). Political and economic determinants of budget deficits in the industrial democracies. European Economic Review, 33, 903-938.

Solé-Ollé, A. (2006). The effects of party competition on budget outcomes: Empirical evidence from local governments in Spain. Public Choice, 126, 145-176.

Volkering, B. \& de Haan, J. (2001). Fragmented government effects on fiscal policy: New evidence. Public Choice, 109, 221-242. 